\title{
Cerebrospinal fluid acid-base status and lactate and pyruvate concentrations after convulsions of varied duration and aetiology in children
}

\author{
H. SIMPSON, A. H. HABEL, AND E. L. GEORGE \\ From the Royal Hospital for Sick Children, Edinburgh, and the Department of Child Life and Health, \\ University of Edinburgh
}

SUMMARY Twenty-two infants and children were studied after convulsions of varied cause and duration. Arterial and CSF acid-base variables, lactate and pyruvate concentrations, and lactate/ pyruvate ratios were measured between 3 and 18 hours after convulsive episodes. Biochemical signs of cerebral hypoxia were found in 7 patients with prolonged ( $>30$ minutes) or recurrent short convulsions. These signs were absent in patients with single short convulsions. These findings indicate that cerebral hypoxia and possible brain damage is a hazard of prolonged or rapidly recurring short convulsions.

In our accompanying paper (Simpson et al., 1977) we showed that first-time febrile convulsions of short duration in children are unlikely to result in cerebral hypoxia. The questions arise whether brief $(<30$ minutes) single or multiple 'nonfebrile' convulsions or prolonged convulsions ( $>30$ minutes), with or without fever, cause cerebral hypoxia with the attendant risk of structural brain damage. Pathological changes may occur in the brains of adults after several hours of status epilepticus (see review by Corsellis, 1971), whereas in children damage has been attributed to seizures of 1-2 hours' duration (Zimmerman, 1938; Fowler, 1957). The mechanism whereby recognized pathological changes (cerebrocortical atrophy, cerebellar atrophy, and mesial temporal sclerosis) are produced in the brains of chronic epileptics is not always certain, but there is a growing suspicion that convulsive hypoxia, especially during prolonged febrile convulsions, gives rise to permanent cerebral lesions (Falconer, 1971; Ounsted, 1971).

The present investigation was undertaken to measure the degree of postulated cerebral hypoxia by the determination of lactate and pyruvate concentrations and lactate/pyruvate ratios in the cerebrospinal fluid (CSF) of children after convulsions of varied duration and aetiology (excluding patients with first febrile convulsions of short duration). An increase in CSF lactate and in lactate/pyruvate ratio

Received 31 March 1977 indicates impairment of cerebral oxidative metabolism (Siesjö and Plum, 1971).

\section{Patients and methods}

Table 1 gives clinical details of the 22 patients in the series. The group comprised 6 females and 16 males (mean age 3.4 years). Patients with first-time febrile convulsions lasting $<\mathbf{3 0}$ minutes were excluded. No other selection criteria were adopted and the 6 children with febrile convulsions (Cases 5-7, 16, 17, 19) are included because of either prolonged convulsions ( $>30$ minutes) or a previous history of similar episodes. The remaining 16 patients had convulsions of varied duration and cause.

A history of an immunization procedure or contact with infectious illness in the preceding 4 weeks was noted in 4 patients (Cases 15-17, 19). Convulsions were most often clonic in type and in 8 children (Cases 1-8) lasted $>30$ minutes. One patient (Case 9) had recurrent short convulsions each lasting approximately 10 minutes over a period of several hours. In 3 patients (Cases 19-21) the duration of convulsions before admission to hospital could not be ascertained. The interval between convulsion and lumbar puncture was not always known precisely and was most often between 4 and 8 hours.

Viruses were isolated from throat or nasal swabs or virus infection inferred serologically by a fourfold rise in titre in paired samples in 5 of 20 patients investigated (Cases 3, 7, 14, 16, 19). In one patient 
Table 1 Clinical details of children with convulsions of varied aetiology and duration

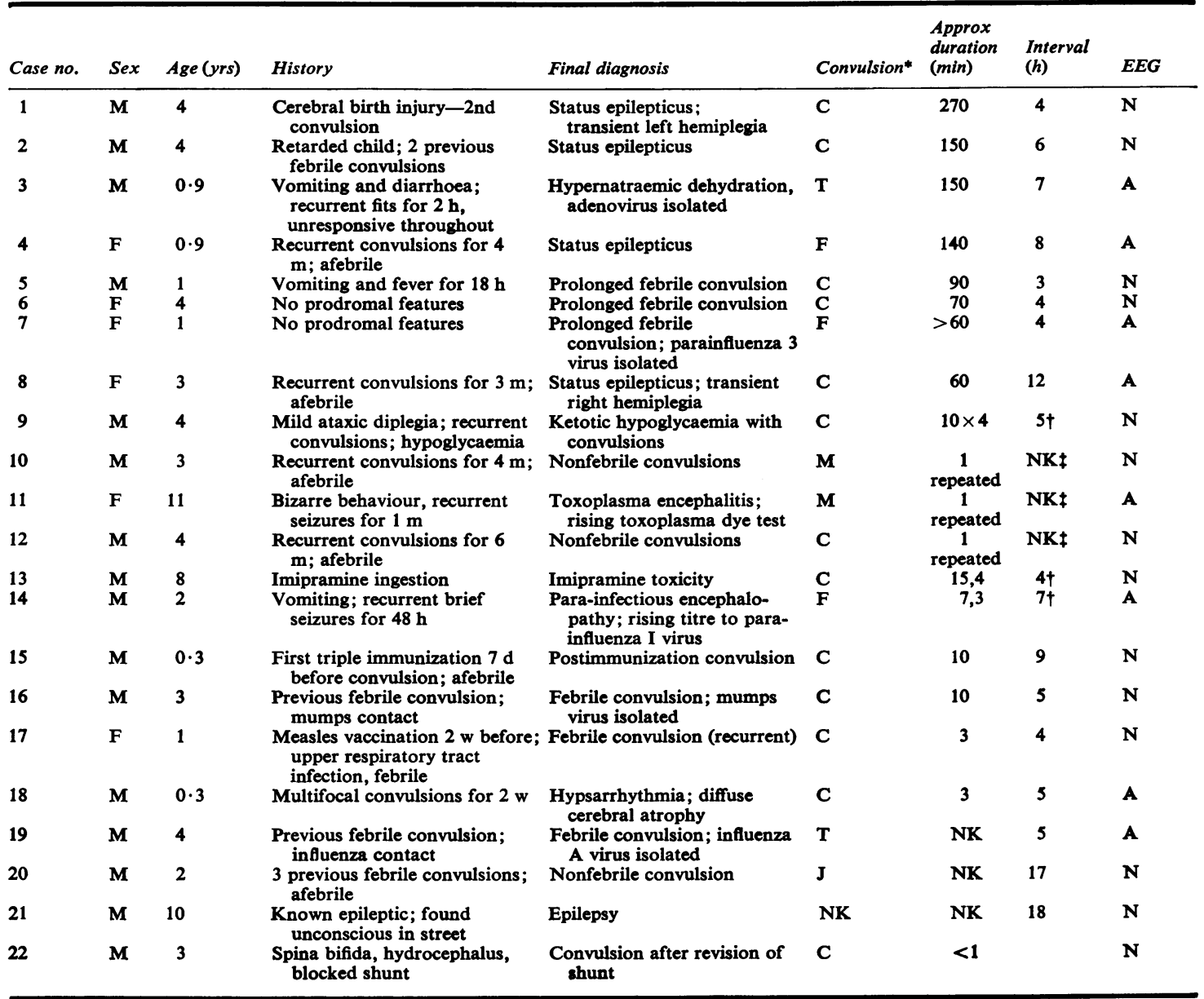

$* \mathrm{C}=$ clonic $; \mathrm{T}=$ tonic $; \mathrm{F}=$ focal $; \mathbf{M}=$ myoclonic, multifocal; $\mathrm{J}=$ jitteriness.

†After last fit.

†Frequent seizures throughout each 24 -hour period.

$\mathbf{N}=$ normal; $\mathbf{A}=$ abnormal.

Medication before lumbar puncture:

Ketamine $5 \mathrm{mg} / \mathrm{kg}$ IM: Cases 4, 6, 8, 10, 16, 17, 19.

Thiopentone $22 \mathrm{mg} / \mathrm{kg}$ rectally: Case 11 .

Chlorpromazine $25 \mathrm{mg}$ IM: Case 12.

Chloral hydrate $500 \mathrm{mg}$ orally: Case 20 .

(Case 11) toxoplasmosis was the final diagnosis. Abnormal electroencephalographic recordings were obtained in 8 patients investigated at least 2 weeks after convulsive episodes.

Before investigation all but 4 patients (Cases 7, 15-17) had received anticonvulsants, usually diazepam $0 \cdot 1-0 \cdot 3 \mathrm{mg} / \mathrm{kg}$ immediately, followed by phenytoin 3-8 $\mathrm{mg} / \mathrm{kg}$ per 24 hours or phenobarbitone 3-7 $\mathrm{mg} / \mathrm{kg}$ per 24 hours. Reduction in intracranial pressure was achieved with $5 \mathrm{ml} / \mathrm{kg} 20 \%$ mannitol (Cases 1, 2) and dexamethasone $2-4 \mathrm{mg}$ four times daily (Cases 2 and 5). The latter also received muscle relaxants and intermittent positive pressure ventilation with oxygen enriched air.

The procedure for obtaining CSF samples and analytical methods are described in our accompanying paper (Simpson et al., 1977). Additional measurements in 11 patients included serum alanine aminotransferase or aspartate aminotransferase, measured in venous samples obtained some 12 to 24 hours after convulsions. Serum alanine transferase was raised $(74 \mathrm{U} / 1)$ in one patient (Case 2). Trans- 
aminase levels were less than $40 \mathrm{U} / 1$ in the remaining 10 cases.

Results

The 22 patients in this series all survived. Their clinical status was reviewed periodically after discharge from hospital for at least one year. The progress and subsequent neurological status of these and our first febrile convulsion patients will be reported separately (Habel and Simpson, 1977).

Acid-base variables. Table 2 gives individual and group values for acid-base variables in arterial blood and CSF. Arterial blood data shows $p \mathrm{H}$ at or near normal in most cases. Arterial $p H$ is $<7.36$ in 3 patients (Cases 1, 3, 20) and $>7.43$ in a further 3 (Cases 17, 18, 22). Negative values of base excess greater than $-5 \mathrm{mmol} / 1$ indicate significant metabolic acidosis (Cases $3,8,19,20$ ) partially compensated by a reduction in $\mathrm{PCO}_{2}$ below $35 \mathrm{mmHg}$ $(4.67 \mathrm{kPa})$. Respiratory alkalosis (Cases 18 and 22$)$ was probably due to transient disturbance during sampling or postictal hyperventilation. Transient disturbance is the most likely explanation when there is a marked difference between arterial and CSF $\mathrm{PCO}_{2}$ (Fisher and Christianson, 1963). Mean $\mathrm{CSF} p \mathrm{H}, \mathrm{PCO}_{2}$, and bicarbonate do not differ signifi- cantly from control values given in our accompanying paper (Simpson et al., 1977).

When corresponding variables in blood and CSF are compared (paired $t$ test) the mean CSF $p \mathrm{H}$ of $7 \cdot 32$ is significantly lower $(\mathrm{P}<0.001)$ and the mean $\mathrm{PCO}_{2}$ of $45 \mathrm{mmHg}(6.00 \mathrm{kPa})$ higher $(\mathrm{P}<0.001)$ than the respective mean arterial $p \mathrm{H}$ of 7.39 and $\mathrm{PCO}_{2}$ of $34 \mathrm{mmHg}(4.53 \mathrm{kPa})$. These are the relationships normally found in adults (Bradley and Semple, 1962). The mean CSF bicarbonate of $22.0 \mathrm{mmol} / 1$ does not differ significantly from the mean bicarbonate of $20.5 \mathrm{mmol} / \mathrm{l}$ in arterial blood.

Lactate and pyruvate. Table 3 gives individual and group values for lactate and pyruvate concentrations and lactate/pyruvate ratios in arterial blood and CSF. Arterial lactate concentration exceeds $2 \cdot 0$ $\mathrm{mmol} / 1(18 \mathrm{mg} / 100 \mathrm{ml})$ in 4 patients (Cases $3,5,9$, 15) and lactate/pyruvate ratio exceeds 16.0 in 7 (Cases 1-3, 8, 9, 16, 20). For each variable values are scattered within a wide range.

CSF lactate exceeds $2 \cdot 1 \mathrm{mmol} / 1(18.9 \mathrm{mg} / 100 \mathrm{ml})$ in 8 patients (Cases $2-5,9,10,13,22$ ) and lactate/ pyruvate ratio exceeds 18.0 in 9 (Cases $2-5,9,10$, $16,17,20)$. However, group mean values for each do not differ significantly (Wilcoxon nonparametric test) from control values given in our accompanying paper (Simpson et al., 1977).

Table 2 Arterial blood and CSF acid-base variables in children with convulsions

\begin{tabular}{|c|c|c|c|c|c|c|c|c|c|}
\hline \multirow[b]{2}{*}{$\begin{array}{l}\text { Case } \\
\text { no. }\end{array}$} & \multicolumn{6}{|l|}{ Blood } & \multicolumn{3}{|l|}{$C S F$} \\
\hline & $\begin{array}{l}P_{O^{2}} \\
(m m H g)\end{array}$ & $p H$ & $\begin{array}{l}P_{C O^{2}} \\
\left(m m_{H}\right)\end{array}$ & $\begin{array}{l}\mathrm{HCO}_{3}^{-} \\
(m m o l l l)\end{array}$ & $\begin{array}{l}\text { Base excess } \\
(\mathrm{mmol} / \mathrm{l})\end{array}$ & $\begin{array}{l}H+ \\
(\text { nmolll) }\end{array}$ & $p H$ & $\begin{array}{l}P_{\mathrm{CO}_{2}} \\
(\mathrm{mmHg})\end{array}$ & $\begin{array}{l}\mathrm{HCO}_{3} \\
(\mathrm{mmol} / \mathrm{l})\end{array}$ \\
\hline 1 & - & $7 \cdot 33$ & 39 & $20 \cdot 0$ & $-4 \cdot 8$ & $49 \cdot 0$ & $7 \cdot 31$ & 52 & $24 \cdot 4$ \\
\hline 2 & 76 & $7 \cdot 43$ & 35 & $23 \cdot 0$ & $-1 \cdot 0$ & $51 \cdot 3$ & $7 \cdot 29$ & 52 & $23 \cdot 6$ \\
\hline 3 & - & $7 \cdot 23$ & 32 & $14 \cdot 5$ & $-14 \cdot 0$ & $44 \cdot 7$ & $7 \cdot 35$ & - & - \\
\hline 4 & - & - & - & - & - & - & - & - & - \\
\hline 6 & - & - & - & - & - & 47.9 & $7 \cdot 32$ & 44 & $21 \cdot 0$ \\
\hline 7 & - & - & - & - & - & - & - & - & - \\
\hline 8 & 87 & $7 \cdot 38$ & 31 & $18 \cdot 0$ & $-6 \cdot 5$ & $46 \cdot 8$ & $7 \cdot 33$ & 48 & $24 \cdot 0$ \\
\hline 9 & - & - & - & - & - & - & - & - & - \\
\hline 10 & 92 & $7 \cdot 38$ & 36 & $21 \cdot 0$ & $-3 \cdot 4$ & $52 \cdot 5$ & $7 \cdot 28$ & 54 & $24 \cdot 0$ \\
\hline 11 & - & - & - & - & - & $49 \cdot 0$ & $7 \cdot 31$ & 51 & $24 \cdot 4$ \\
\hline 12 & - & - & - & - & - & - & - & - & - \\
\hline 13 & - & - & - & - & - & $49 \cdot 0$ & $7 \cdot 31$ & 51 & $24 \cdot 8$ \\
\hline 14 & - & - & - & - & - & - & - & - & - \\
\hline 17 & 102 & $7 \cdot 44$ & 43 & $29 \cdot 0$ & $+5 \cdot 0$ & $46 \cdot 8$ & $7 \cdot 33$ & 40 & $20 \cdot 2$ \\
\hline 18 & 96 & $7 \cdot 44$ & 29 & $19 \cdot 3$ & $-3 \cdot 5$ & $45 \cdot 7$ & $7 \cdot 34$ & 34 & $17 \cdot 5$ \\
\hline 19 & 93 & $7 \cdot 41$ & 29 & $18 \cdot 1$ & $-5 \cdot 8$ & 47.9 & $7 \cdot 32$ & 45 & $22 \cdot 0$ \\
\hline 20 & 72 & $7 \cdot 32$ & 34 & $17 \cdot 1$ & $-8 \cdot 5$ & $45 \cdot 7$ & $7 \cdot 34$ & 37 & $19 \cdot 1$ \\
\hline 21 & - & $7 \cdot 41$ & 39 & $24 \cdot 4$ & 0 & $49 \cdot 0$ & $7 \cdot 31$ & 44 & $21 \cdot 0$ \\
\hline 22 & 87 & $7 \cdot 49$ & 27 & $20 \cdot 8$ & $-2 \cdot 5$ & $46 \cdot 8$ & $7 \cdot 33$ & 40 & 20.6 \\
\hline Mean & 88 & $7 \cdot 39$ & 34 & $20 \cdot 5$ & $-4 \cdot 0$ & $47 \cdot 8$ & $7 \cdot 32$ & 45 & $22 \cdot 0$ \\
\hline \pm SD & $10 \cdot 02$ & 0.07 & $4 \cdot 58$ & 3.61 & $4 \cdot 48$ & $2 \cdot 31$ & 0.02 & 6.01 & $2 \cdot 18$ \\
\hline $\pm S E$ & $3 \cdot 54$ & 0.02 & $1 \cdot 27$ & 1.00 & $1 \cdot 24$ & 0.58 & 0.01 & $1 \cdot 55$ & 0.56 \\
\hline $\begin{array}{l}\text { Range } \\
\mathbf{n}\end{array}$ & $\begin{array}{l}72-102 \\
9\end{array}$ & $\begin{array}{l}7 \cdot 23-7 \cdot 49 \\
13\end{array}$ & $\begin{array}{l}27-43 \\
13\end{array}$ & $\begin{array}{l}17 \cdot 1-29 \cdot 0 \\
13\end{array}$ & $\begin{array}{l}-14 \cdot 0-+5 \cdot 0 \\
13\end{array}$ & $\begin{array}{l}43 \cdot 7-52 \cdot 5 \\
16\end{array}$ & $16^{7 \cdot 28-7 \cdot 37}$ & $\begin{array}{l}34-54 \\
15\end{array}$ & $\begin{array}{l}17 \cdot 5-24 \cdot 8 \\
15\end{array}$ \\
\hline
\end{tabular}

Conversion: $S I$ to traditional units- $\mathrm{PO}_{2}, \mathrm{PCO}_{2}: 1 \mathrm{kPa} \approx 7.5 \mathrm{mmHg} . \mathrm{HCO}_{3}$, base excess: $1 \mathrm{mmol} / 1=1 \mathrm{mEq} / \mathrm{l}$. 
Table 3 Arterial blood and CSF lactate and pyruvate concentrations and lactate/pyruvate ratios in children with convulsions

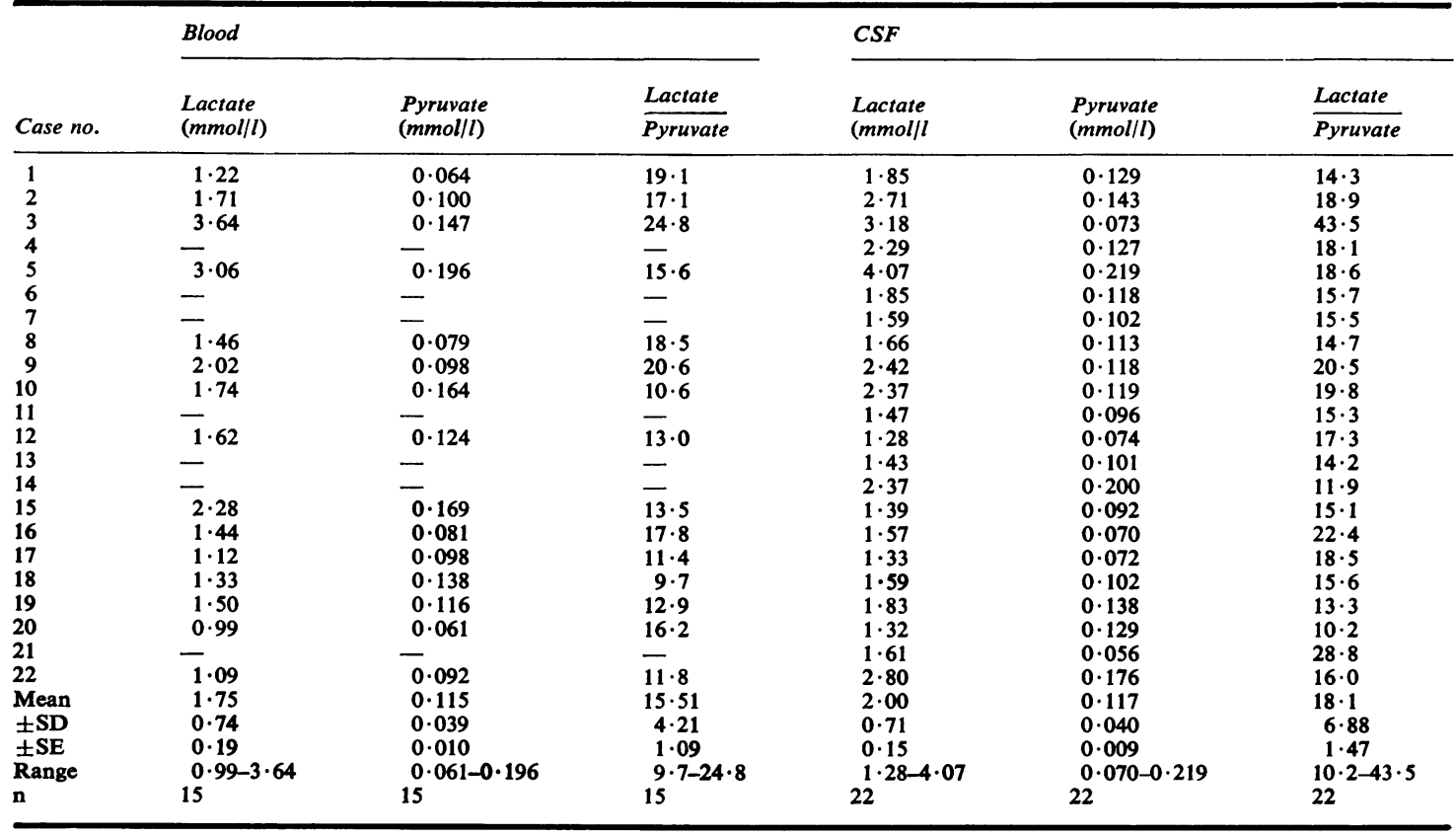

No significant differences were found on comparing CSF and blood with respect to lactate and pyruvate concentrations and lactate/pyruvate ratios (paired $t$ test). There was no significant correlation between CSF lactate and CSF $p \mathrm{H}, \mathrm{PCO}_{2}$, or bicarbonate.

Duration of convulsions. In the present series, 8 children (Cases 1-8) had convulsions exceeding 30 minutes and in 4 (Cases 2-5) CSF lactate concentrations and lactate/pyruvate ratios were raised. Normal values for these variables were obtained in one patient (Case 1) thought to have 'convulsed' for over 4 hours before arrival in hospital.

Six patients (Cases 9-14) had short repeated convulsions and 2 showed evidence of cerebral hypoxia by the same criteria (Cases 9 and 10). Of the remaining 8 (Cases 15-22), 5 were known definitely to have had single convulsions of short duration and none showed an increase in both CSF lactate concentration and lactate/pyruvate ratio. Table 4 summarizes our main findings, including patients in the first febrile convulsion series (Simpson et al., 1977). When convulsions are recurrent or prolonged there is a significant increase in the proportion of patients with a raised CSF lactate concentration, lactate/pyruvate ratio, and with both, compared with single short convulsions. These findings support the view that cerebral hypoxia following convulsions is related to their duration and is most likely after prolonged or repeated convulsions, whatever the aetiology.

\section{Discussion}

Studies about systemic and cerebral metabolic changes following brief epileptic seizures are mentioned in our accompanying paper (Simpson et al., 1977). Corresponding information about seizures sufficiently long and severe to produce brain damage is also available for baboons (Meldrum and Horton, 1973; Meldrum and Brierley, 1973), but understandably not for experimental seizures in humans. There is also little information about the metabolic changes during spontaneous grand mal convulsions either in adult man (Brooks and Adams, 1975) or children (Blennow and Svenningsen, 1974), and it seems important to determine whether the changes which occur parallel those seen experimentally.

Arterial blood findings show that mild to moderate metabolic acidosis occurs in many patients in the postictal period with minimal change in CSF acidbase status. The CSF arterial blood difference for bicarbonate is consistent with metabolic acidosis. Similar findings are reported by Brooks and Adams 
Table 4 CSF lactate and pyruvate concentrations and lactate/pyruvate ratios in relation to duration of convulsions (including data from accompanying paper on febrile convulsions)

\begin{tabular}{|c|c|c|c|c|}
\hline Duration* & No. & $\begin{array}{l}\text { Lactate } \\
>2 \cdot 1(\mathrm{mmol} / \mathrm{l})\end{array}$ & $\begin{array}{l}\text { Lactate/pyruvate } \\
>18 \cdot 0\end{array}$ & 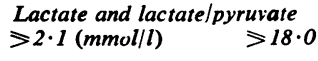 \\
\hline Single $<30 \mathrm{~min}$ & 31 & 4 & 4 & 1 \\
\hline Single $>30 \mathrm{~min}$ & 8 & 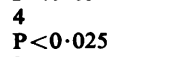 & 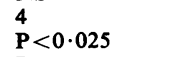 & 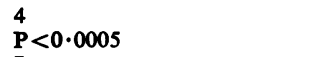 \\
\hline $\begin{array}{l}\text { Repeated and } \\
\text { single }>30 \mathrm{~min}\end{array}$ & 17 & $\begin{array}{l}8 \\
P<0.01\end{array}$ & 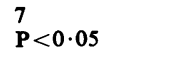 & 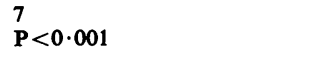 \\
\hline
\end{tabular}

*Excludes cases 19-21 (Table 1) where duration of convulsions was uncertain.

$P$ values from $2 \times 2$ contingency tables using $\chi^{2}$ distribution.

(1975) for adult patients studied 3 and 6 hours after idiopathic seizures.

The blood lactate concentration was raised in several of our patients (Table 3). This could result not only from hypoxaemia and increased muscle activity, but also from hyperventilation, liver dysfunction, catecholamine release, the use of anaesthetic agents, or infusion of sodium bicarbonate (Oliva, 1970). Arterial blood lactate was not increased in the one patient with abnormal liver function (Case 2) or in those children given ketamine before lumbar puncture (Table 1). Sodium bicarbonate infusion did not precede sampling of blood or CSF in the patients studied.

CSF lactate exceeded $2 \cdot 1 \mathrm{mmol} / 1(18 \cdot 9 \mathrm{mg} / 100 \mathrm{ml})$ (the upper limit of normal for controls) in 8 patients. This increase could have resulted directly from cerebral metabolic changes during the seizure, ictal or postictal hyperventilation, or the transfer of lactate from blood to CSF. If the hypothesis is correct that an increase in both CSF lactate concentration and in lactate/pyruvate ratio indicates cerebral hypoxia (Siesjö and Plum, 1971), this was present in only 6 of our patients. Our individual measurements (Table 3) are not strictly comparable as they were made between 3 and 18 hours after convulsions. This variation in timing was unavoidable as most convulsive episodes occurred outside hospital and a varying period had elapsed before hospital admission and subsequent lumbar puncture. However, most of our samples were taken between 4 and 8 hours after convulsions when an increased CSF lactate may persist even when blood lactate concentration has returned to normal (Posner and Plum, 1967). Lumbar puncture was avoided in the first 3 hours after convulsion to permit time for equilibration between brain, cisternal, and lumbar CSF lactate and pyruvate. No attempt was made to repeat the lumbar punctures during the study and the optimal time for sampling remains uncertain.

The inter-relationship between hypoxaemia, hypercapnia, and ischaemia on the energy state of the brain in nonconvulsing experimental animals has been investigated by Siesjö and his colleagues (Siesjö, 1971/72; Siesjö and Plum, 1971). Hypoxaemia per se may result in an increased lactate and lactate/pyruvate ratio in brain tissue without concomitant reduction in the energy state of the brain. However, a combination of ischaemia and hypoxaemia leads to pronounced lactate acidosis and a fall in energy potential. Even then, the combined hypoxaemic/ischaemic insult has to be great before histological changes are produced (Salford et al., 1971/72).

Studies of prolonged epileptic seizures in primates (Meldrum and Brierley, 1973) have shown ischaemic changes after bicuculline-induced seizures lasting between 1 and 5 hours. Brain damage appeared to occur after the first half hour at a stage in the seizure when there was associated hyperpyrexia, arterial hypotension, systemic hypoxaemia, acidosis, and occasionally severe hypoglycaemia. Generalized seizures lasting up to 5 hours sometimes led to brain damage or death. Muscle paralysis and artificial ventilation protect against cortical and hippocampal damage during prolonged seizures and prevent cerebellar damage which is thought to be related to hyperpyrexia and arterial hypotension (Meldrum et al., 1973). It is unlikely that our patients suffered hypoxic insult of this degree. All were treated with anticonvulsants and every attempt was made to maintain oxygenation and correct metabolic upsets during observed seizures. Only a careful follow-up of single short and prolonged febrile convulsions will show which patients have recurrences and possible 'hypoxic' brain damage. However, our results support the view that prolonged or recurrent convulsions of whatever aetiology may cause cerebral hypoxia, which in turn might contribute to the production of local or diffuse structural changes. The 30-minute 'safe' period suggested is necessarily somewhat arbitrary, but there is increasing agreement that more prolonged convulsions $(>\mathbf{3 0}$ minutes) are potentially harmful (Aicardi and Chev- 
rie, 1970; Aicardi and Baraton, 1971). It might also be inferred from the experimental work of Wasterlain and Plum (1973) and Wasterlain (1976) in immature rats that the developing human brain, especially in infancy, is particularly vulnerable to convulsive hypoxia. Thus in children under one year the 'safe' period might be less than 30 minutes.

We have given evidence of cerebral hypoxia in children following recurrent or prolonged convulsions and metabolic trends similar to those seen experimentally. The clinical implications seem clear. Every attempt should be made to stop generalized seizures as early as possible. Oxygenation should be maintained throughout convulsions and metabolic and acid-base derangements corrected. If anticonvulsants are ineffective (e.g. over a 30-minute period) muscle paralysis and mechanical ventilation should be considered in further management.

We thank Professor J. O. Forfar for his support, and consultant colleagues for allowing us to include patients under their care; Dr. J. M. Inglis and his staff who carried out virological investigations at the City Hospital, Edinburgh; and Mrs. D. Tervit who typed the manuscripts.

\section{References}

Aicardi, J., and Baraton, J. (1971). A pneumoencephalographic demonstration of brain atrophy following status epilepticus. Developmental Medicine and Child Neurology, 13, 660-667.

Aicardi, J., and Chevrie, J. J. (1970). Convulsive status epilepticus in infants and children. A study of 239 cases. Epilepsia, 11, 187-197.

Blennow, G., and Svenningsen, N. W. (1974). Cerebrospinal fluid lactate/pyruvate ratio in children with febrile convulsions. Neuropaediatrie, 5, 157-161.

Bradley, R. D., and Semple, S. J. G. (1962). A comparison of certain acid-base characteristics of arterial blood, jugular venous blood and cerebrospinal fluid in man, and the effect of them on some acute and chronic acid-base disturbances. Journal of Physiology, 160, 381-391.

Brooks, B. R., and Adams, R. D. (1975). Cerebrospinal fluid acid-base and lactate changes after seizures in unanesthetized man. Neurology, 25, 935-942.

Corsellis, J. A. N. (1971). The neuropathology of human epilepsy with particular reference to status epilepticus. Brain Hypoxia, pp. 263-265. Ed. by J. B. Brierley and
B. S. Meldrum. Clinics in Developmental Medicine 39/40 Heinemann, London.

Falconer, M. A. (1971). Genetic and related aetiological factors in temporal lobe epilepsy. Epilepsia, 12, 13-31.

Fisher, V. J., and Christianson, L. C. (1963). Cerebrospinal fluid acid-base balance during a changing ventilatory state in man. Journal of Applied Physiology, 18, 712-716.

Fowler, M. (1957). Brain damage after febrile convulsions. Archives of Disease in Childhood, 32, 67-76.

Habel, A. H., and Simpson, H. (1977). Neurological and biochemical correlation at follow-up of children suffering febrile convulsions. In preparation.

Meldrum, B. S., and Brierley, J. B. (1973). Prolonged epileptic seizures in primates: ischemic cell change and its relation to ictal physiological events. Archives of Neurology, 28, 10-17.

Meldrum, B. S., and Horton, R. W. (1973). Physiology of status epilepticus in primates. Archives of Neurology, 28, 1-9.

Meldrum, B. S., Vigouroux, R. A. and Brierley, J. B. (1973). Systemic factors and epileptic brain damage. Archives of Neurology, 29, 82-87.

Oliva, P. (1970). Lactic acidosis. American Journal of Medicine, 48, 209-225.

Ounsted, C. (1971). Some aspects of seizure disorders. Recent Advances in Paediatrics, 4th ed., pp. 363-400. Ed. by D. Gairdner and D. Hull. Churchill, London.

Posner, J. B., and Plum, F. (1967). Independence of blood and cerebrospinal fluid lactate. Archives of Neurology, 16, 492-496.

Salford, L. G., Brierley, J. B., Plum, F., and Siesjö, B. K. (1971/72). Energy metabolism and histology in the brain during combined hypoxemia and ischemia. European Neurology, 6, 329-334.

Siesjö, B. K. (1971/72). Metabolism and flow in the hypoxic brain. European Neurology, 6, 43-48.

Siesjö, B. K., and Plum, F. (1971). Cerebral energy metabolism in normoxia and in hypoxia. Acta Anaesthesiologica Scandinavica, Suppl. 45, 81-101.

Simpson, H., Habel, A. H., and George, E. L. (1977). Cerebrospinal fluid acid-base status and lactate and pyruvate concentrations after short $(<30$ minutes) first febrile convulsions in children. Archives of Disease in Childhood, 52, 836-843.

Wasterlain, C. G. (1976). Effects of neonatal status epilepticus on rat brain development. Neurology, 26, 975-986.

Wasterlain, C. G., and Plum, F. (1973). Vulnerability of developing rat brain to electroconvulsive seizures. Archives of Neurology, 29, 38-45.

Zimmerman, H. M. (1938). The histopathology of convulsive disorders in children. Journal of Pediatrics, 13, 859-890.

Correspondence to Dr. H. Simpson, Department of Child Life and Health, University of Edinburgh, Hatton Place, Edinburgh. 